\title{
PENERAPAN PERAWATAN PAYUDARA PADA PASIEN POST NATAL CARE (PNC) TERHADAP KEBERHASILAN MENYUSUI
}

\author{
Ani Lestari ${ }^{1}$, Lena Atoy $^{1}$, H. Taamu ${ }^{1}$ \\ ${ }^{1}$ Poltekkes Kemenkes Kendari Jurusan Keperawatan
}

\begin{abstract}
ABSTRAK
Post Natal Care dimulai sejak 2 jam pertama setelah lahirnya plasenta sampai dengan 6 minggu/42 hari setelah itu. Selama masa nifas, ibu akan mengalami perubahan fisiologis. Perubahan terjadi pada sistem reproduksinya. Perubahan pada sistem reproduksi tersebut diantaranya adalah payudara (mamae), involutio uterus, pengeluaran lokia, perubahan pada endometrium, serviks, vulva dan vagina, dan pada perineum. Data menunjukkan jumlah persalinan normal pada tahun 2015 jumlah ibu nifas sebanyak 589 orang (64\%), tahun 2016 jumlah ibu nifas sebanyak 931 orang (65\%), tahun 2017 sebanyak 1.230 orang (67\%), tahun 2018 sebanyak 804 orang. Studi kasus ini bertujuan untuk mengetahui keberhasilan penerapan perawatan payudara terhadap keberhasilan menyusui maternal pada pasien Post Natal Care (PNC). Desain studi kasus ini adalah menggunakan desain penelitian deskriptif dengan bentuk penerapan studi kasus dengan subjek studi kasus menggunakan satu orang pasien sesuai dengan kriteria inklusi dan eksklusi yang telah ditetapkan. Data diperoleh dengan pengkajian dan wawancara secara langsung kepada pasien serta dokumen-dokumen yang ada Di Rumah Sakit. Hasil studi kasus ditemukan bahwa penerapan perawatan payudara efektif dalam meningkatkan volume produksi ASI yang keluar. Bagi Rumah Sakit diharapkan dapat menambah dan mengembangkan ilmu yang sudah ada serta meningkatkan mutu pelayanan kesehatan khususnya untuk penerapan perawatan payudara pada Ibu Post Partum dengan masalah payudara dan ASI.
\end{abstract}

\section{Kata Kunci : Nifas, Perawatan Payudara}

\section{PENDAHULUAN}

Proses persalinan merupakan suatu proses kompleks untuk menyelamatkan ibu dan bayinya dengan menggunakan berbagai macam metode seperti persalinan pervaginaan, persalinan dengan menggunakan alat dan persalinan operatif yaitu melalui Sectio
Caesarea (SC). Metode tersebut dilakukan dengan indikasi-indikasi khusus dengan satu tujuan yaitu menyelamatkan ibu maupun janinnya (Larasati, 2012).

Post natal care atau masa nifas merupakan masa kritis baik bagi ibu maupun bayinya maka diperlukan 
asuhan keperawatan pada masa nifas. Masa nifas dimulai sejak 2 jam pertama setelah lahirnya plasenta sampai dengan 6 minggu/42 hari setelah itu. Selama masa nifas, ibu akan mengalami perubahan fisiologis. Perubahan terjadi pada sistem reproduksinya. Perubahan pada sistem reproduksi tersebut diantaranya adalah payudara (mamae), involutio uterus, pengeluaran lokia, perubahan pada endometrium, serviks, vulva dan vagina, dan pada perineum (Maritalia, 2012).

Berdasarkan studi awal yang dilakukan peneliti di Rumah Sakit Umum Dewi Sartika pada bulan Januari 2019 bahwa jumlah ibu nifas mengalami peningkatan setiap tahunnya. Pada tahun 2015 jumlah ibu nifas sebanyak 589 orang (64\%), tahun 2016 jumlah ibu nifas sebanyak 931 orang $(65 \%)$, tahun 2017 sebanyak 1.230 orang (67\%), tahun 2018 sebanyak 804 orang.

Perawatan payudara sering disebut Breast Care bertujuan untuk memelihara kebersihan payudara, memperbanyak atau memperlancar pengeluaran ASI. Perawatan payudara dilakukan dengan cara masase, pengompresan, dan perawatan putting susu (Anggraini Y, 2010).

Keberhasilan menyusui adalah pembentukan perlekatan yang tepat dari ibu ke bayi untuk mengisap payudara sebagai makanan selama 3 minggu pertama menyusui. Proses pembentukan ASI dimulai sejak awal kehamilan, ASI (Air Susu Ibu) diproduksi karena pengaruh faktor hormonal, proses pembentukan ASI dimulai dari proses terbentuknya laktogen dan hormonhormon yang mempengaruhi terbentuknya ASI. Dalam pembentukan hormon-hormon untuk terbentuknya ASI bisa melalui rangsangan dari perawatan payudara. (Bulechek, 2013).

\section{Metode Penelitian}

Desain studi kasus ini adalah menggunakan desain penelitian deskriptif dengan bentuk penerapan studi kasus. Hasil yang diharapkan oleh peneliti adalah keberhasilan menyusui dan kelancaran ASI dalam penerapan teknik perawatan payudara pada pasien Post Natal Care (PNC) terhadap keberhasilan menyusui di Ruang Nifas Rumah Sakit Umum Dewi Sartika Kota Kendari.

Subyek pada penelitian ini adalah pasien yang menerima pelayanan Post Natal Care (PNC) dengan perawatan Payudara di Ruang Nifas Rumah Sakit Umum Dewi Sartika Kendari.

Sumber data yang digunakan dalam penelitian ini adalah data primer dan data sekunder. Data primer yaitu data yang didapatkan lansung kepada klien baik itu melalui proses pengkajian dan wawancara terhadap responden (klien atau keluarga klien). Sedangkan data sekunder dalam penelitian ini adalah data yang diperoleh dari status klien dan rekam medis di Rumah Sakit Umum Dewi Sartika Kota Kendari.

\section{Hasil Studi Kasus}

Pengkajian dilakukan didapatkan data identitas Ibu dan Suami, pasien berinisial $\mathrm{Ny}$. $\mathrm{N}$ berumur 25 tahun, beragama Islam, pendidikan terakhir SD dengan pekerjaan sebagai Ibu Rumah Tangga dan beralamat Di Baruga. Suami pasien berinisial Tn. J berumur 28 tahun, beragama Islam, pendidikan terakhir SD dengan pekerjaan sebagai Petani dan beralamat Di Baruga.

Berdasarkan data dari pengkajian yang dilakukan merujuk pada batasan karakteristik ketidkcukupan ASI pada diagnose keperawatan NANDA, maka 
terdapat kesesuaian data dan diagnose keperaawatan tersebut. Peneliti menegakkan diagnose ketidakcukupan ASI, berdasarkan Nursing Intervention Classification (NIC) penerapan perawatan payudara dapat meningkatkan produksi ASI dan melancarkan pengeluaran ASI.

\section{Pembahasan Studi Kasus}

Post Natal Care (PNC) dalam keberhasilan menyusui didapatkan hasil pada hari pertama sebelum dilakukan perawatan payudara dari tiga standar outcomes yang ditetapkan $\mathrm{Ny}$. $\mathrm{N}$ hanya berada pada skala 1 sampai 2 yaitu tidak adekuat dan sedikit adekuat dan terjadi peningkatan pengeluaran ASI pada hari ke tiga yaitu skala 5 atau sepenuhnya adekuat

Peningkatan pengeluaran ASI yang adekuat dapat dipengaruhi dengan berbagai faktor, antara lain : mengkonsumsi sayur-sayuran, klien kooperatif dalam melakukan perawatan payudara selama 3 hari dengan frekuensi 2x sehari. Manfaat dari perawatan payudara adalah : merangsang kelenjarkelenjar air susu sehingga produksi ASI banyak dan lancar, dapat mendeteksi kelainan-kelainan payudara secara dini, mempersiapkan mental ibu untuk menyusui.

Perawat bertindak sebagai pendukung dan pemberi pendidikan ketika menggunakan teknik perawatan payudara untuk keberhasilan menyusui pada pasien Post Natal Care (PNC). Peneliti mencoba melakukannya dengan cara membimbing dan mengaplikasikan langsung pada pasien berdasarkan prosedur perawatan payudara yang sudah disusun. Pasien yang diberi perawatan payudara memperhatikan apa yang dilakukan kemudian mampu melakukan perawatan payudara secara mandiri.

Penelitian yang dilakukan pada hari pertama tanggal 23 April 2019 didapatkan hasil dari ketiga standar skala outcomes yang ditetapkan yaitu skala 1 (tidak adekuat) dan setelah dilakukan perawatan payudara pada $\mathrm{Ny}$. $\mathrm{N}$ pada tanggal 23 April 2019 pukul ) 08:40 dan 16:00 didapatkan hasil dari ketiga skala outcomes adalah : payudara penuh sebelum menyusui skala 2 (sedikit adekuat), pengeluaran ASI yang adekuat sakal 1 (tidak adekuat), dan teknik pencegahan nyeri putting susu skala 1 (tidak adekuat). Pengeluaran ASI belum lancar disebabkan oleh pasien baru pertama kali menerima perawatan payudara, anaknya masih belum menghisap putting susu, dan klien masih kurang kooperatif dalam melakukan perawatan payudara. Hal ini didukung oleh teori Rustam (2012) sejak hari pertama sampai hari keenam setelah persalinan, ketika ASI secara normal dihasilkan, payudara menjadi sangat penuh dan dengan penghisapan yang efektif oleh bayi serta perawatan payudara yang rutin, rasa penuh pada payudara akan pulih dengan cepat, namun akan terjadi bendungan ketika tidak dilakukan dengan efektif.

Penelitian yang dilakukan pada hari kedua tanggal 24 April 2019 didapatkan hasil dari ketiga standar skala outcomes yang ditetapkan pada pukul 08:00 dan 16:00 skala yang didapatkan dari standar outcomes adalah: payudara penuh sebelum menyusui skala 3 (cukup adekuat), penegluaran ASI yang adekuat skala 2 (sedikit adekuat), teknik untuk mencegah nyeru putting susu skala 3 (cukup adekuat). Terjadi perubahan pada pengeluaran ASI pada pasien, hal ini dikarenakan pasien sudah mulai 
membiasakan anaknya untuk menhisap putting susu, sudah kooperatif dalam melakukan perawatan payudara dengan bantuan penulis, dan pasien sudah sering memakan sayur-sayuran. Hal ini didukung oleh teori Yuliana Intan (2010) bendungan ASI dapat terjadi dikarenakan oleh pengosongan ASI yang kurang efektif.

Penelitian yang dilakukan pada hari ketiga tanggal 25 April 2019 didapatkan hasil dari ketiga standar skala outcomes pada pukul 08:00 didapatkan hasil : payudara penuh sebelum menyusui skala 4 (sebagian besar adekuat), pengeluaran ASI yang adekuat skala 4 (sebagian besar adekuat), dan teknik pencegahan nyeri putting susu skala 4 (sebgaian besar adekuat). Dan pada pukul 16:00 didapatkan hasil : payudara penuh sebelum menyusui skala 5 (sepenuhnya adekuat), penegluaran ASI yang adekuat skala 5 (sepenuhnya adekuat), teknik mencegah nyeri putting susu skala 5 (sepenuhnya adekuat). Hal ini disebabkan oleh perawatan payudara yang dilakukan secara rutin baik dibantu oleh penulis maupun dilakukan secara mandiri oleh pasien, pengosongan yang efektif yang dilakukan dengan menyusui anaknya dengan durasi yang lama. Hal ini didukung oleh teori Yuliana Intan (2010) untuk mengatasi bendungan ASI yang terjadi pada ibu Post Natal Care dianjurkan agar tetap menyusui bayinya supaya tidak terjadi stasis dalam payudara yang cepat menyebabkan terjadinya masitis.

Terdapat kesamaan hasil penelitian dimana terjadi perubahan produksi ASI yang keluar. Kesamaan ini dikarenkana perawatan payudara yang dilakukan seacara berulang dapat merangsang kelenjar-kelenjar produksi ASI sehingga pengeluaran ASI menjadi lancar dan banyak. Proses penghisapan bayi ke putting susu dapat menjadi rangsangan terhadap ASI yang keluar melalui putting susu Ibu, sehingga keberhasilan menyusui didapatkan setelah dilakukan perawatan payudara selama 3 hari yang dilakukan 2x sehari.

\section{Kesimpulan}

Berdasarkan hasil penelitian yang dilakukan pada $\mathrm{Ny}$. $\mathrm{N}$ dapat disimpulkan tidak ditemukan kesenjangan signifikan antara teori dan hasil penelitian yang didapatkan. Kepulan yang didapatkan dari penelitian adalah sebagai berikut :

1. Pengkajian

Pengkajian dilakukan pada tanggal 23 April 2019 pada pukul 08:00 WITA dari pengkajian tersebut didapatkan data identitas Ibu dan Suami, pasien berinisial $\mathrm{Ny}$. $\mathrm{N}$ berumur 25 tahun, beragama Islam, pendidikan terakhir SD dengan pekerjaan sebagai Ibu Rumah Tangga dan beralamat Di Baruga

2. Diagnosa Keperawatan

Berdasarkan data yang didapatkan dari hasil pengkajian yang dilakukan pada Ny. $\mathrm{N}$ penulis menegakkan atau mengangkat diagnosa keperawatan : Ketidakcukupan ASI berhubungan dengan Kurangnya Produksi ASI, karena batasan karakteristik yang paling banyak ditemukan mengacu pada diagnosa tersebut.

3. Intervensi Keperawatan

Penerapan perawatan payudara pada Ny. $\mathrm{N}$ dilakukan selama 3 hari dengan frekuensi $2 \mathrm{x}$ sehari (pagi dan sore) dengan interval waktu 8 jam dengan tujuan berdasarkan NOC adalah keberhasilan menyusui dengan kriteria hasil : payudara penuh sebelum menyusui, pengeluaran ASI yang 
adekuat, dan teknik mencegah nyeri putting susu.

4. Implementasi Keperawatan

Adapun implementasi keperawatan yang dilakukan pada Ny. $\mathrm{N}$ adalah : melakukan perawatan payudara yang meliputi : pemijatan (masase), perawatan putting susu, dan pengompresan payudara. Tindakan ini diberikan selama 3 hari dan dilakukan $2 \mathrm{x}$ sehari yaitu pada pagi hari dan sore hari.

5. Evaluasi Keperawatan

Evaluasi keperawatan merupakan proses akhir dari pemberian asuhan keperawatan yang memuat kriteria hasil dan keberhasilan tindakan dengan melihat tingkat kemajuan kesehatan pasien.

\section{DAFTAR PUSTAKA}

Ambarwati. (2009). Asuhan Kebidanan Nifas. Yogyakarta : Mitra Cendikia.

Andriyani, $\quad$ Fiffy. (2018). PenerapanKompresDingin Pada Pasien Post Natal Care (PNC) Dengan Luka Perineum DalamPemenuhanKebutuhan Rasa Nyaman (Nyeri) Di Ruang Laika WarakaObstetri Dan Gynekologi RSU. Bahteramas Prov. Sultra.Kendari.

Anggraini Y. (2010). Asuhan Kebidanan Masa Nifas. Yogyakarta : Pustaka Rihama.

Anonim. (2011). Perawatan Payudara Pada Ibu Masa Nifas. http://www.solusikewanitaan.com/2011/ 10/perawatan-payudara-masa-nifas.html. diperoleh tanggal 06 Desember 2018.

Aspiani, R.Y. (2017). Buku Ajar Asuhan Keperawatan Maternitas Aplikasi
NANDA NIC NOC. Jakarta : CV Trans Info Media.

Assangadah, Putiwi. (2017). Asuhan Keperawatan Dengan Penerapan Teknik Perawatan Payudara (Breast Care) Untuk Meningkatkan Produksi ASI Pada Ibu Menyususi Di Ruang Bougenvil Rumah Sakit Umum Dareah Dr. Soedirman. Kebumen.

Astutik, R.Y. (2014). Payudara Dan Laktasi. Yogyakarta : Salemba Medika.

Bulechek, Gloria M. \& Butcher Howard K. dkk. (2013). Nursing Intervention Classification (NIC) Edisi Keenam. Jakarta : Elsevier.

Dermawan, D. (2012). Proses Keperawatan Perencanaan Konsep Dan Kerangka Kerja. Yogyakarta : Gosyen Publishing.

Dinas Kesehatan Provinsi Sulawesi Tenggara. (2017). Profil Kesehatan Sulawesi Tenggara 2017.

Herdinan, T. H. \& Kamitsuru, S. (2015). Diagnosis Keperawatan Definisi \& Klasifikasi 2015-2017 Edisi 10. Jakarta: EGC.

Hutahaean, Serri. (2009). Asuhan Keperawatan Dalam Maternitas \& Ginekologi. Jakarta: Transinfomedia.

Jenny. (2009). Perawatan Masa Nifas Ibu Dan Bayi "Pemulihan Pasca Melahirkan Bagi Para Ibu Dan Perawatan Bayi Selama Nifas". Yogyakarta : Sahabat Setia.

Jitowiyono, A., \& Kristianasara, W. (2010). Asuhan Keperawatan Post 
Operasi Dengan Pendekatan NANDA NIC NOC. Yogyakarta : Nuha Medika.

Kementrian Kesehatan RI. (2017). Profil Kesehatan Indonesia Tahun 2017. Jakarta: Kemenetrian Kesehatan RI 2017.

Krisdayanasari, Weni. (2009). ASI, Menyusui \& Sadari. Yogyakarta : Nuha Medika.

Larasati. (2012). Asuhan Keperawatan Pada Ny. D Dengan Post SC Atas Indikasi Insufisiensi Plasenta Di Ruang An Nisa RS Pku Muhammadiyah Surakarta. Karya Tulis Ilmiah. Amd.Kep, Fakultas Ilmu Kesehatan Universitas Muhammadiyah. Surakarta

Mardila, Ayu. (2018). Pengaruh Perawatan Payudara Terhadap Kelancaran Ekskresi ASI Pada Ibu Post Partum Di Rumah Bersalin Mardi Rahayu Semarang. Diperoleh tanggal 08 Desember 2018, dari http://download.portalgaruda.org/article. php? article $=393153 \&$ val $=6378 \&$ title $=\mathrm{P}$ ENGARUH\%20PERAWATAN\%20PA YUDARA\%20TERHADAP\%20KELA NCARAN\%20EKSKRESI\%20ASI\%20 PADA\%20IBU\%20POST\%20PARTU M\%20DI\%20RUMAH\%20BERSALIN \%20MARDI\%20RAHAYU\%20SEMA

RANG.

Maritalia. (2012). Asuhan Kebidanan Nifas Dan Menyusui. Yogyakarta : Pustaka Belajar.

Moorhead, Sue \& Johnson Marion, dkk. (2013). Nursing Outcomes Classification (NOC) Edisi Kelima. Jakarta : Elsevier.
Notoatmodjo, S. (2012). Promosi Kesehatan Dan Perilaku Kesehatan. Jakarta : Rineka Cipta.

Nurarif, A. H. \& Kusuma, H. (2015). Aplikasi Asuhan Keperawatan Berdasarkan Diagnosa Medis dan Nanda Nic-Noc Edisi Revisi 1. Yogyakarta: MediAction.

Nursalam. (2011). Konsep Dan Penerapan Metedologi Penelitian Ilmu Keperawatan : Pedoman Skripsi, Tesis, Dan Instrumen Penelitian Keperawatan. Jakarta : Salemba Medika.

Puspita, Diana. (2017). Asuhan Keperawatan Dengan Penerapan Breast Care Untuk Meningkatkan Produksi ASI Pada Pasien Post Natal Care Di Ruang Bougenvil Rumah Sakit Umum Daerah. Dr. Soedirman. Kebumen.

Reski, Ayu. (2016). Produksi ASI pada Pasien Post PartusDi Rumah Sakit Yogyakarta. Diperoleh tanggal 21 Januari 2019, dari http://repository.unimus.ac.id

Sastrawinata. (2009). Konsep Dasar Persalinan. Jakarta : EGC.

Werdinan, Yuni. (2018). Definisi dan langkah-Langkah Perawatan Payudara. Diperoleh tanggal 08 Desember 2018, dari

http://bangsalsehat.blogspot.com/2018/0 6/sop-breastcare.

Wheeler, Linda. (2009). Perawatan Pranatal \& Pascapartum. Jakarta: EGC.

Wijayanti. (2015). Hubungan Breast Care dengan Kelancaran Asi pada Pasien Post Partum Di Rumah Sakit Umum Padang. Padang 
Wiknjosastro. (2010). Buku Panduan Praktis Pelayanan Kesehatan Maternal Dan Neonatal Edisi 1. Jakarta : Bina Pustaka.
Yuli, R. (2017). Buku Ajar Asuhan Keperawatan Maternitas, Aplikasi NANDA NIC Dan NOC. Jakarta : TIM. 